\title{
Review of: "Text messages to support e-cigarette use for smoking cessation: a tool for researchers"
}

\author{
Ayça Balmumcu ${ }^{1}$ \\ 1 Adnan Menderes University
}

Potential competing interests: The author(s) declared that no potential competing interests exist.

E cigarette is used today as a smoking cessation tool. However, studies in the literature have shown that e-cigarettes are not effective in smoking cessation(1,2,3,4). People who use e cigarettes can define themselves as non-smoking. At this point, the study presents a combined method by creating a text message supported program as a method to help ecigarette users to quit smoking. It is available in the literature that combined methods are more effective in smoking cessation. The absence of a study in which text messages with e-cigarettes is used in the literature makes the study original. From my perspective, getting suggestions from e-cigarette users while composing messages in the study is an important step in creating effective messages. I think that the present study could serve as a basement for future research in the creation of text message supported programs regarding quitting e-cigarette.

1. Vickerman KA, Carpenter KM, Altman T, Nash CM, Zbikowski SM. Use of electronic cigarettes among state tobacco cessation quitline callers. Nicotine Tob Res 2013; 15: 1787-91.

2. Grana R, Popova L, Ling PM. A longitudinal analysis of electronic cigarette use and smoking cessation. JAMA Intern Med 2014; 174: 812-3.

3. Choi K, Forster JL. Beliefs and experimentation with electronic cigarettes: a prospective analysis among young adults. Am J Prev Med 2014; 46: 175-8.

4. Adkison SE, O'Connor RJ, Bansal-Travers M, Hyland A, Borland R, Yong HH, et al. Electronic nicotine delivery systems: international tobacco control four-country survey. Am J Prev Med 2013; 44: 207-15. 